\title{
Identification of building heating systems as controlled objects within automated heat supply stations
}

\author{
Alexey Sergeevich Soldatenkov \\ Department of electrical engineering and automatics \\ Belgorod State Technological University named after \\ V.G. Shoukhov \\ BSTU named after V.G. Shoukhov \\ Belgorod, Russia \\ 308012, Kostukov St., 46 \\ soldatenkov.as@bstu.ru
}

\author{
Evgeny Anatolyevich Potapenko \\ Department of electrical engineering and automatics \\ Belgorod State Technological University named after \\ V.G. Shoukhov \\ BSTU named after V.G. Shoukhov \\ Belgorod, Russia \\ 308012, Kostukov St., 46 \\ popapenko@intbel.ru
}

\author{
Olga Vladimirovna Parashchuk \\ Department of electrical engineering and automatics \\ Belgorod State Technological University named after V.G. Shoukhov \\ BSTU named after V.G. Shoukhov \\ Belgorod, Russia \\ 308012, Kostukov St., 46 \\ paraschuk_ov@rambler.ru
}

\begin{abstract}
This article concentrates on the analysis of building heating systems as controlled objects within the dispatching automated power system of a group of buildings. As a result of experiments, main control, perturbation influence, and the controlled variable - heating system return temperature - are defined. These data form the basis of a developed mathematical model by means of a structural diagram with the use of Laplace transformation. The effect of outer air temperature on the output signal behaviour and the range of the coefficient of a model equation is shown by experiments. To determine coefficients of the transfer function over the main control channel parametric identification of the controlled object was performed and the given model adequacy was shown. This approach forms the basis of mathematical and simulation modelling of distributed power systems of a group of buildings for the purpose of rationalization of energy resources consumption. The obtained results show the possibility to construct distributed groups of buildings with various levels of automation.
\end{abstract}

Keywords- Mathematical model, heating system, automation, parametric identification, energy saving.

\section{INTRODUCTION}

The use of automatic control in heating supply systems of buildings allows improving the quality of their performance and reducing the thermal energy consumption. It is provided by local systems of automatic control in automated control stations which allow regulation of temperature and the coolant rate. The development of automated heat consumption control systems of buildings is a key element of a 'smart house' concept and is partially presented in papers [1-3]. The use of the automated control station of building allows saving heat energy up to $30 \%$ in the transition periods of the heating season $[4,5]$.

The papers [6-8] present that for the buildings with enclosure structures, heat transmission resistance is inconsistent with standard. The use of the automated dispatch control system of building heat supply allows significantly reducing the thermal energy consumption, but only if monthly mean temperatures are higher than average in the heating season (for example, warm winter). Otherwise, the effect of automated system implementation results in the lack of thermal energy overconsumption with no need for additional winterization, but in a certain temperature range. In this connection, it is essential to take energy-efficiency measures associated with thermal energy saving by implementation of automated control stations of buildings integrated into the structure of automated dispatch control system. The current information on consumption of actual energy resources will allow one to proactively manage distributed power systems on the basis of simulation modelling of building heat supply processes, and repository data will provide optimal solution in planning energy resources consumption. However, in such setting of a problem, it is necessary to have an adequate mathematical model of building the heating system as the controlled object.

\section{RESULTS AND DISCUSSION}

To determine basic relation between coolant rates and coolant temperatures in the building heating system, as well as 
the properties of the heating system as the controlled object, a scheme with direct connection to the heating energy source on the basis of automated control station was studied. In a simplified form, such scheme with basic experimental variables of coolant is shown in Fig. 1. The schematic symbols are the following: $\mathrm{K} 1$ is a motorized regulating valve $\mathrm{M} 3, \mathrm{KO} 1$ is a back flow preventer with a jumper, $\mathrm{H} 1$ and $\mathrm{H} 2$ are monoblock units of circulation pumps with electric drives M1 and M2. $G_{1}, T_{1}$ and $G_{2}, T_{2}$ are correspondingly coolant rates and coolant temperatures at the input into the automated control station in flow and return pipes. $T_{01}$ and $T_{02}$ are correspondingly coolant temperatures in the building heating system in flow and return pipes, $G_{0}$ is a coolant rate in the building heating system, $G_{3}$ is a coolant rate through the jumper with KO1.

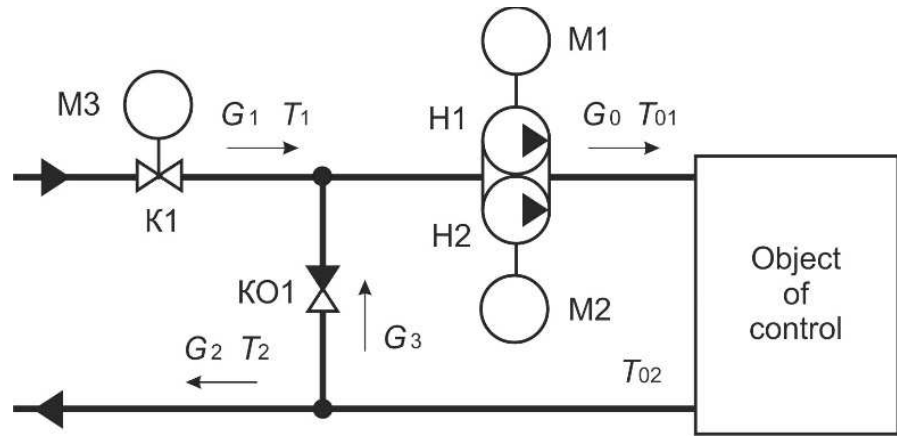

Fig. 1. Simplified scheme of direct connection of the building heating system on the basis of the automated control station to the heat source.

Typical experimental dynamic characteristics in adjustment links "coolant rate $G_{1}$ - temperature $T_{01}$ " and "coolant rate $G_{1}$ - temperature $T_{02}$ " obtained by step change of coolant rate $G_{1}$ are shown in Fig. 2 . The adjustment link " $G_{1}-$ $T_{01}$ " is determined by the region of mixing coolant from the flow pipe and the jumper with foot valve. With circulation pumps $\mathrm{H} 1$ and $\mathrm{H} 2$ which initiate the flow of coolant, the mixing process is almost prompt [9], meaning that change of $G_{1}$ (curve 1 in Fig. 2, b) initiates step change of $T_{01}$ at the initial instant (curve 2 in Fig. 2, a). The dynamics of adjustment link " $G_{1}-T_{02}$ " is determined by pipe branching and the range of the heating system, as well as by the type of heating appliance. The dependence of $T_{02}(t)$ (curve 3 in Fig. 2, a) is smooth, including step change of $T_{01}$ that can be explained by considerable response time of heating system branches when coolant flows through them. The transient period on the adjustment link " $G_{1}-T_{02}$ " equals to several hours. Thus, the heating system offers properties of a low-pass filter.

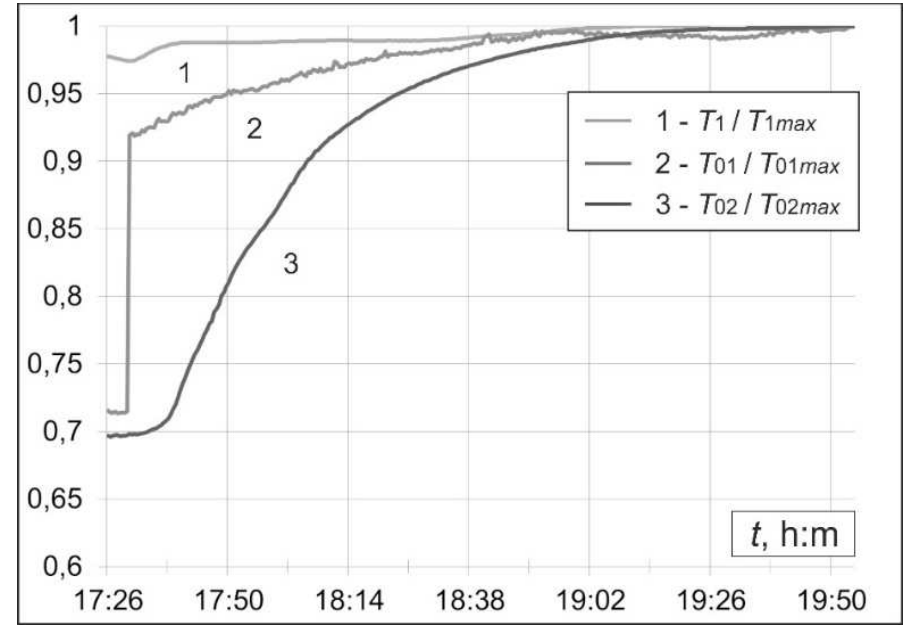

a

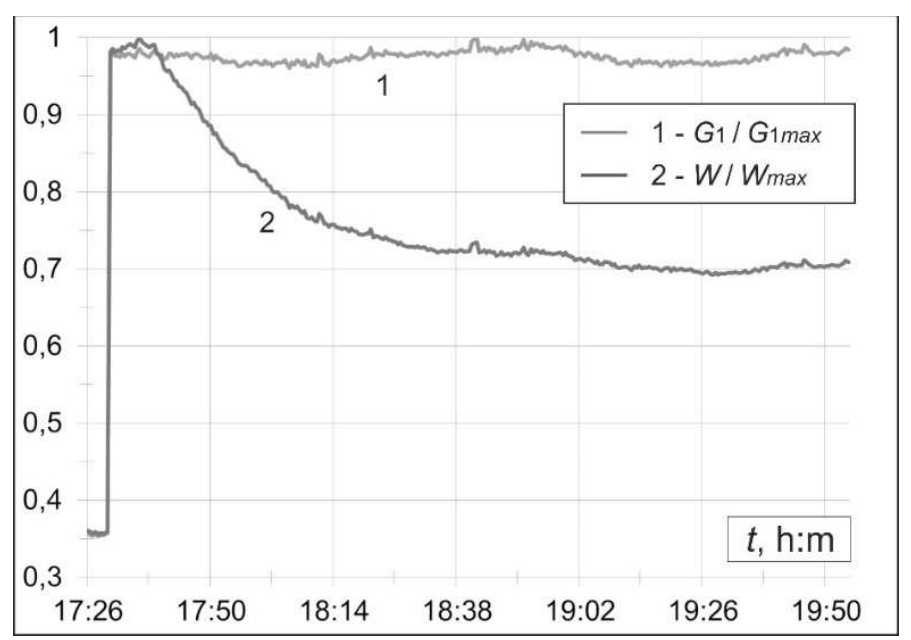

b

Fig. 2. Experimental typical reduced characteristics of dynamic: $a$ - coolant temperature $T_{1}(1), T_{01}(2), T_{02}(3), b$ - coolant rate $G_{1}(1)$, thermal power $W$ (2).

The analysis of Fig. 1 and typical dynamic characteristics of the heating system shows that input variables are coolant rate $G_{1}$ determined by the position of a stem of regulation seated valve (K1) with actuation mechanism (M3), and coolant temperature $T_{1}$ determined by operation mode of the heating energy source. The temperature of supplied coolant $T_{01}$ is regulated by mixing coolant from the heating system with temperature $T_{1}$ and coolant rate $G_{1}$, and coolant from the return pipe through the jumper with temperature $T_{02}$ coolant rate $G_{3}$. This explains the following dynamics of temperature $T_{01}$ in the heating system (curve 2 in Fig. 2,a). As coolant rate $G_{0}$ determined by circulation pumps $\mathrm{H} 1$ and $\mathrm{H} 2$ is permanent, from the law of conversation of mass there is the relation:

$$
G_{3}(t)=G_{0}-G_{1}(t) .
$$

Assuming the possibility of transient response ignorance in the mixing region considering that the speed of coolant flow is much less than the sound velocity, the conversation law of amount of heat in the coolant mixing unit is as follows: 


$$
G_{0} T_{01}(t)=G_{1}(t) T_{1}(t)+G_{3}(t) T_{02}(t) .
$$

Therefore, the heating system control problem amounts to regulation of coolant temperature $T_{01}$ at the input of the building heating system by mixing coolants with temperatures $T_{1}$ and $T_{02}$. In these conditions, the main controlling quantity is the coolant rate $G_{1}$ at the input to the automated control station (Fig. 1). At the same time, variable $T_{02}$ appeared in the equation is defined by the heating system parameters and properties of enclosures, and is also subjected to various perturbation influences and primarily to environmental conditions.

To estimate the bond character between temperatures $T_{01}$ and $T_{02}$ taking into account the complexity of the heating system, it is meaningful to perform the controlled object identification by typical experimental dynamic characteristics, e.g., using the least-squares method. On the basis of S-shaped experimental typical dynamic characteristics of coolant temperatures in the building heating system, the equation of the controlled object motion is defined as:

$$
\tau_{1} \tau_{2} \frac{d^{2} T_{02}(t)}{d t^{2}}+\left(\tau_{1}+\tau_{2}\right) \frac{d T_{02}(t)}{d t}+T_{02}(t)=k T_{01}(t)
$$

The time constants $\tau_{1}, \tau_{2}$ and a conversion coefficient $k$ depend on a variety of the heating system, enclosure properties and climatic factors. Fig. $3 a$ shows comparative graphs of reduced experimental (acc.to data in Fig. 2,a) and specified (acc.to the equation (3) with values $\tau_{1}=591 \mathrm{~s}, \tau_{2}=$ $895 \mathrm{~s}, k=0.68)$ temperatures $T_{02}(t)$. In this case mismatch error shown in Fig. 3, by balue doesn't exceed $1.2{ }^{\circ} \mathrm{C}$.

\section{The temperature $T_{02} / T_{02} \max$}

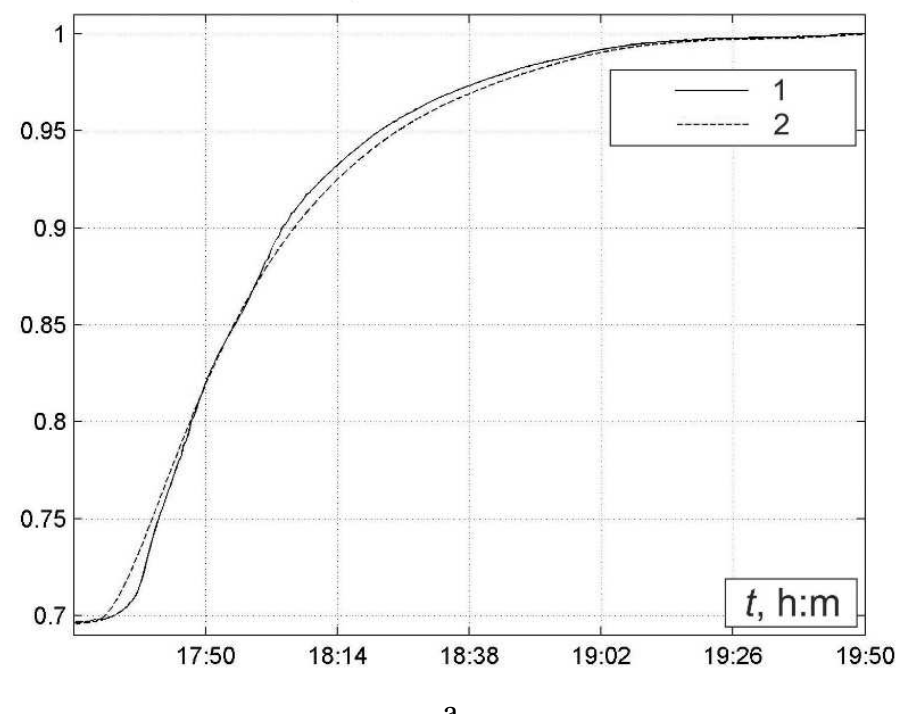

The temperature $T_{02}$

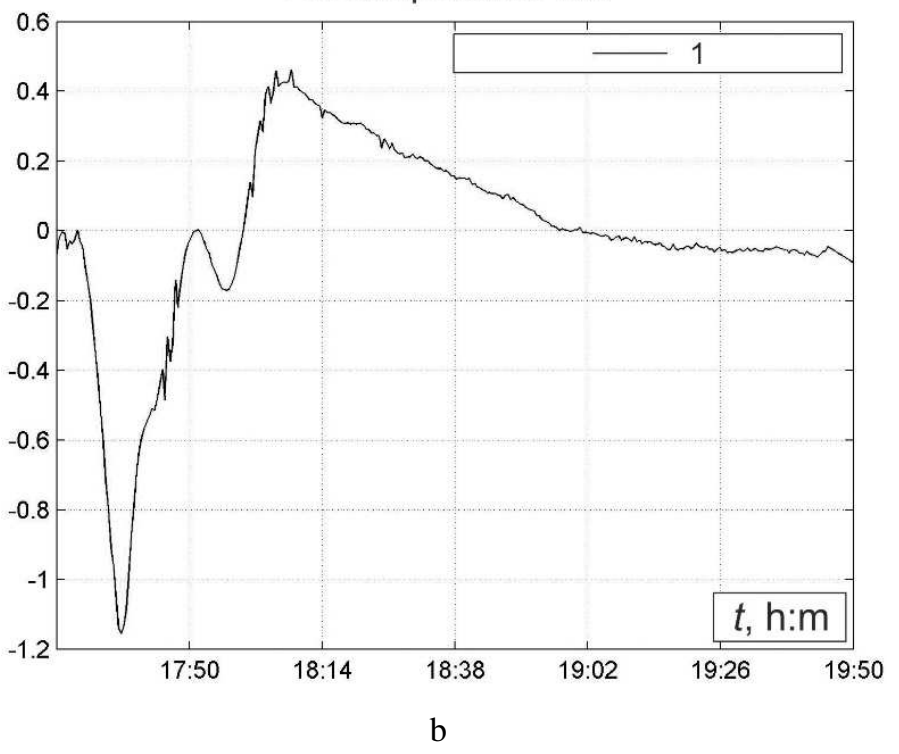

Fig. 3. Comparative graph: $a$ - reduced temperatures $T_{02}(1-$ experimental curve, 2 - specified curve), $b$ - mismatch error.

In accordance with equations (1) - (3), the mathematical model of the building heating system in direct connection to the heat source as the controlled object is given in Fig. 4 in the form of a structural scheme:

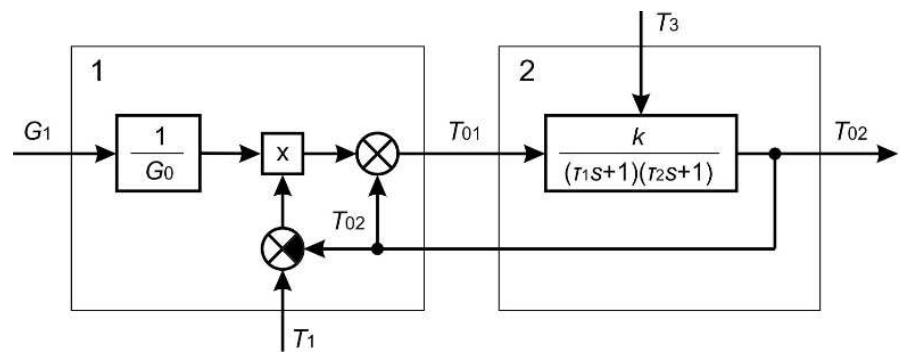

Fig. 4. The structural scheme of the building heating system as the controlled object: 1 - mixing unit, 2 - the heating system.

The analysis of experimental data $[6,10]$ on the daily samples shows that parameters $k, \tau_{1}, \tau_{2}$ vary within a narrow range and are outer air temperature dependent $\left(T_{3}\right)$. In a first approximation, it is advisable to define these dependencies as linear. Fig. 5 shows graphs of coolant reduced temperatures $T_{02}$ in the return pipe with three values of temperatures $T_{3}$ and unchanged (stabilized) temperature $T_{01}$. 


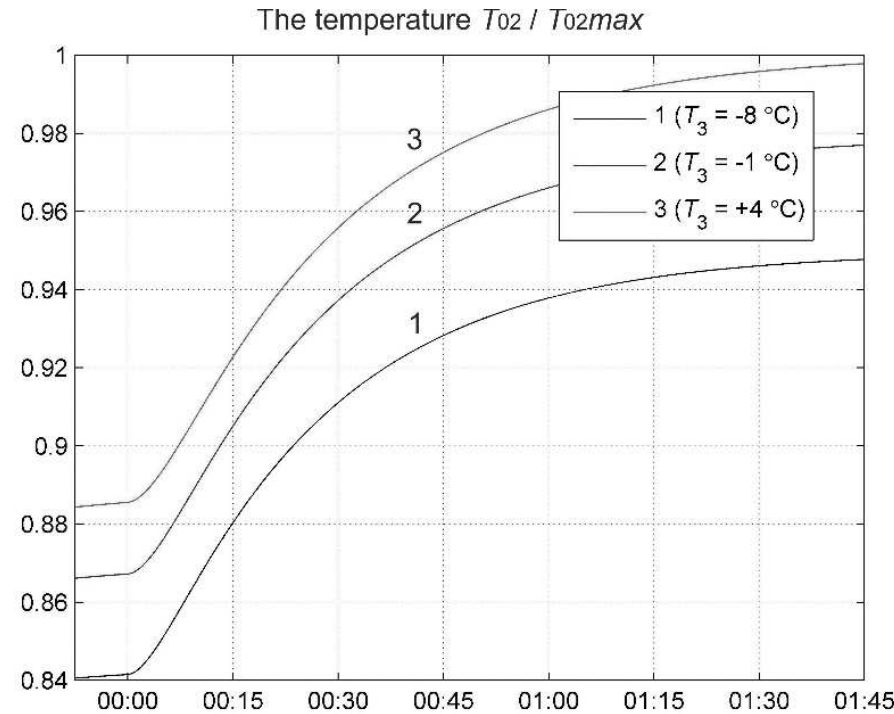

Fig. 5. Graphs of dependencies of reduced temperatures $T_{02}$ with various values of temperature $T_{3}$ : curve $1-$ with $T_{3}=-8{ }^{\circ} \mathrm{C}$, curve $2-$ with $T_{3}=-1{ }^{\circ} \mathrm{C}$, curve 3 - with $T_{3}=+4{ }^{\circ} \mathrm{C}$.

It follows from Fig. 5 that with the rise of temperature $T_{3}$ the coefficients $k, \tau_{1}, \tau_{2}$ grow: $k$ grows from 0,787 to $0,829, \tau_{1}$ - from $216 \mathrm{~s}$ to $282 \mathrm{~s}, \tau_{2}-$ from $1530 \mathrm{~s}$ to $1588 \mathrm{c}$. The nature of this dependence stems from the fact that with the outer air temperature change, the building heat consumption changes and, as a consequence, there is temperature drop between flow and return pipes of the heating system. Taking into account the complexity of analytic definition of coefficient values $k, \tau_{1}, \tau_{2}$ with various temperatures $T_{3}$, it is advisable to apply simulation modelling following from the results of experimental studies of heating systems, as well as to perform parametric identification of the controlled object in accordance with the equation (3).

The purpose of parametric identification of the building heating system as the controlled object is to define the estimated parameters having properties of nonbias, consistency, efficiency and sufficiency. The most common parametric identification methods are least-squares methods, intermediate variables method, maximum likelihood method, stochastic approximation and correlational method which allow us to define on experimental data the estimated parameters of the controlled object with the known structure of its mathematical model. At the same time if external actions represent flat noise and the least-squares method is used, information on the distribution law of random values is not necessary.

According to the equation (3) the model of the building heating system on the adjustment link "temperature $T_{01}-$ temperature $T_{02}$ " (Fig. 4) may be structurally presented as a series connection of two aperiodic links:

$$
W(s)=\frac{k}{\left(\tau_{1} s+1\right)\left(\tau_{2} s+1\right)} .
$$

As during experimental studies measurement of continuous signals is taken at specific time intervals, it is necessary to change a continuous model to discrete, wherefore the authors apply Tustin's transformation [11] to equation (4):

$$
\left.W(s)\right|_{s=\frac{2}{\tau_{0}} \frac{z-1}{z+1}} \rightarrow W(z),
$$

where $z=e^{s \tau_{0}}, \tau_{0}-$ sampling time.

Taking into account relation (5), equation (4) in the form of the discrete transfer function is defined as:

$$
\begin{aligned}
& W(z)=k \tau_{0}^{2}\left(z^{2}+2 z+1\right) /\left(\left(4 \tau_{1} \tau_{2}+2 \tau_{0} \tau_{1}+\right.\right. \\
& \left.+2 \tau_{0} \tau_{2}+\tau_{0}^{2}\right) z^{2}+\left(2 \tau_{0}^{2}-8 \tau_{1} \tau_{2}\right) z+4 \tau_{1} \tau_{2}- \\
& \left.-2 \tau_{0} \tau_{1}-2 \tau_{0} \tau_{2}+\tau_{0}^{2}\right)
\end{aligned}
$$

In this case, the following designations are used:

$$
\left\{\begin{array}{l}
b_{0}=\frac{k \tau_{0}^{2}}{4 \tau_{1} \tau_{2}+2 \tau_{0} \tau_{1}+2 \tau_{0} \tau_{2}+\tau_{0}^{2}}, \\
b_{1}=\frac{8 \tau_{1} \tau_{2}-2 \tau_{0}^{2}}{4 \tau_{1} \tau_{2}+2 \tau_{0} \tau_{1}+2 \tau_{0} \tau_{2}+\tau_{0}^{2}}, \\
b_{2}=\frac{2 \tau_{0} \tau_{1}+2 \tau_{0} \tau_{2}-4 \tau_{1} \tau_{2}-\tau_{0}^{2}}{4 \tau_{1} \tau_{2}+2 \tau_{0} \tau_{1}+2 \tau_{0} \tau_{2}+\tau_{0}^{2}} .
\end{array}\right.
$$

Considering constant coefficients (7), equation (6) takes on the following form:

$$
\begin{aligned}
& W(z)=\left(b_{0}\left(z^{2}+2 z+1\right)\right) /\left(z^{2}-b_{1} z-b_{2}\right)= \\
& =\left(b_{0}\left(1+2 z^{-1}+z^{-2}\right)\right) /\left(1-b_{1} z^{-1}-b_{2} z^{-2}\right) .
\end{aligned}
$$

The finite-difference equation describing the discrete model of the building heating system on the adjustment link "temperature $T_{01}$ - temperature $T_{02}$ " received with the use of $z$ transformation properties [12], takes on the following form:

$$
\begin{aligned}
& y[n]-b_{1} y[n-1]-b_{2} y[n-2]= \\
& =b_{0}(u[n]+2 u[n-1]+u[n-2])
\end{aligned}
$$

where $u$ - input signal, $y$ - output.

According to the known $N$ experimental values $u[n]$ and $y[n]$, taking into account relation (9) in the vector-matrix form, the system of the finite-difference equation is defined:

$$
\Psi B=Y,
$$

where $\Psi$ - extended data matrix, B - vector of the model estimated parameters, $\mathrm{Y}$ - vector of output signal: 


$$
\Psi=\left[\begin{array}{ccc}
y[0] & y[1] & u[2]+2 u[1]+u[0] \\
y[1] & y[2] & u[3]+2 u[2]+u[1] \\
\vdots & & \\
y[N-2] & y[N-1] & u[N]+2 u[N-1]+u[N-2]
\end{array}\right],
$$$$
\mathrm{B}=\left[\begin{array}{l}
b_{2} \\
b_{1} \\
b_{0}
\end{array}\right] \text {, }
$$$$
\mathrm{Y}=\left[\begin{array}{c}
y[2] \\
y[3] \\
\vdots \\
y[N]
\end{array}\right]
$$

To find the values of evaluation vector $\mathrm{B}$, it is advisable to use the least-squares method minimizing a residual sum of squares $e$. The main formula of the least-squares method in a matrix form in accordance with the introduced notations (11) is as follows:

$$
\mathrm{B}=\left(\Psi^{T} \Psi\right)^{-1} \Psi^{T} \mathrm{Y} .
$$

With the use of the least-squares method, the received estimates as a rule are shifted. To reduce errors, it is important to perform smoothing on one transient response, for example, by the method of sliding average, and it is also necessary to fulfil some conditions:

- input signal has to be rather rich in the spectral ratio that is equivalent to infeed rate of a variety of harmonic components;

- the volume of the sample $N$ has to be adequate in order to receive representative estimates, moreover, the lower the level of test signal is, the greater the number $N$ is.

The adequacy of the controlled object and the obtained model can be estimated with the help of loss function in a form of:

$$
E=\frac{1}{N} \sum_{k=1}^{N} e^{2}=\frac{1}{N} \sum_{k=1}^{N}(\hat{y}[k]-y[k])^{2}
$$

where $N$ - sample depth, $e$ - residual, $y$ - output signal, $\hat{y}$ output signal estimate received by means of the model as a result of identification.

For numerical solution of the equation (12), experimental studies of the building heating systems were carried out in order to define typical dynamical characteristics of the adjustment link "temperature $T_{01}$ - temperature $T_{02}$ " based on educational buildings of BSTU named after V.G. Shoukhov (Belgorod, Russia) in transient heating seasons (autumn, spring). The sample depth equals $N=500$ values, the sampling time is $\tau_{0}=115 \mathrm{~s}$. Input $T_{01}(t)$ and output $T_{02}(t)$ coolant temperatures in the heating system of one of the buildings are represented in Fig. 6.

The analysis of Fig. 6 shows that the transient period on the link "temperature $T_{01}$ - temperature $T_{02}$ " exceeds several hours, and due to the response time of the heating system, the controlled object has the properties of a low-pass filter. For the conducted experiment, estimates of transfer function coefficients of the controlled object (4) have the following values: $k=0,8, \tau_{1}=305,55 \mathrm{~s}, \tau_{2}=1071,78 \mathrm{~s}$; the loss function value determined by equation (13) equals $E=0,068$.

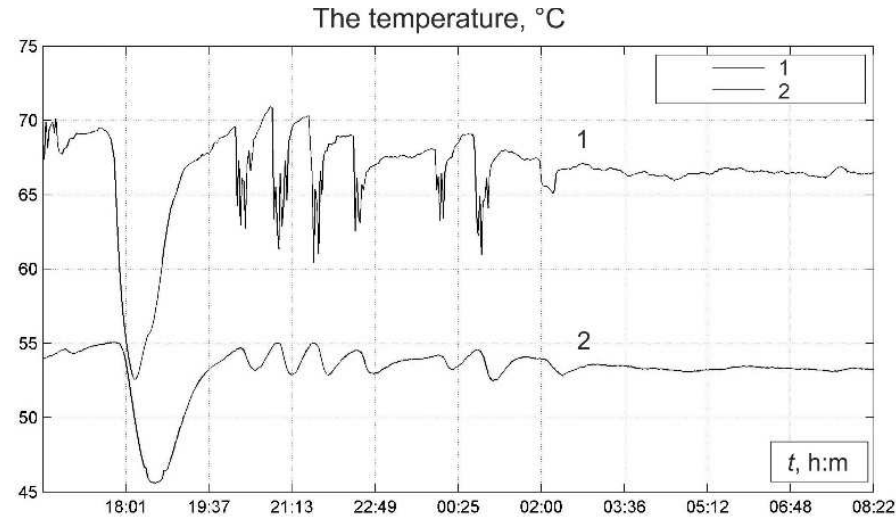

Fig. 6. Graphs of coolant temperatures in the heating system pipes: 1 - input signal $T_{01}, 2-$ output signal $T_{02}$.

In Fig. 7, $a$, there are comparative experimental $T_{02}(t)$ and curve of output temperatures, received by means of the mathematical least-squares method; in Fig. 7, $b$ - mismatch error (residual):
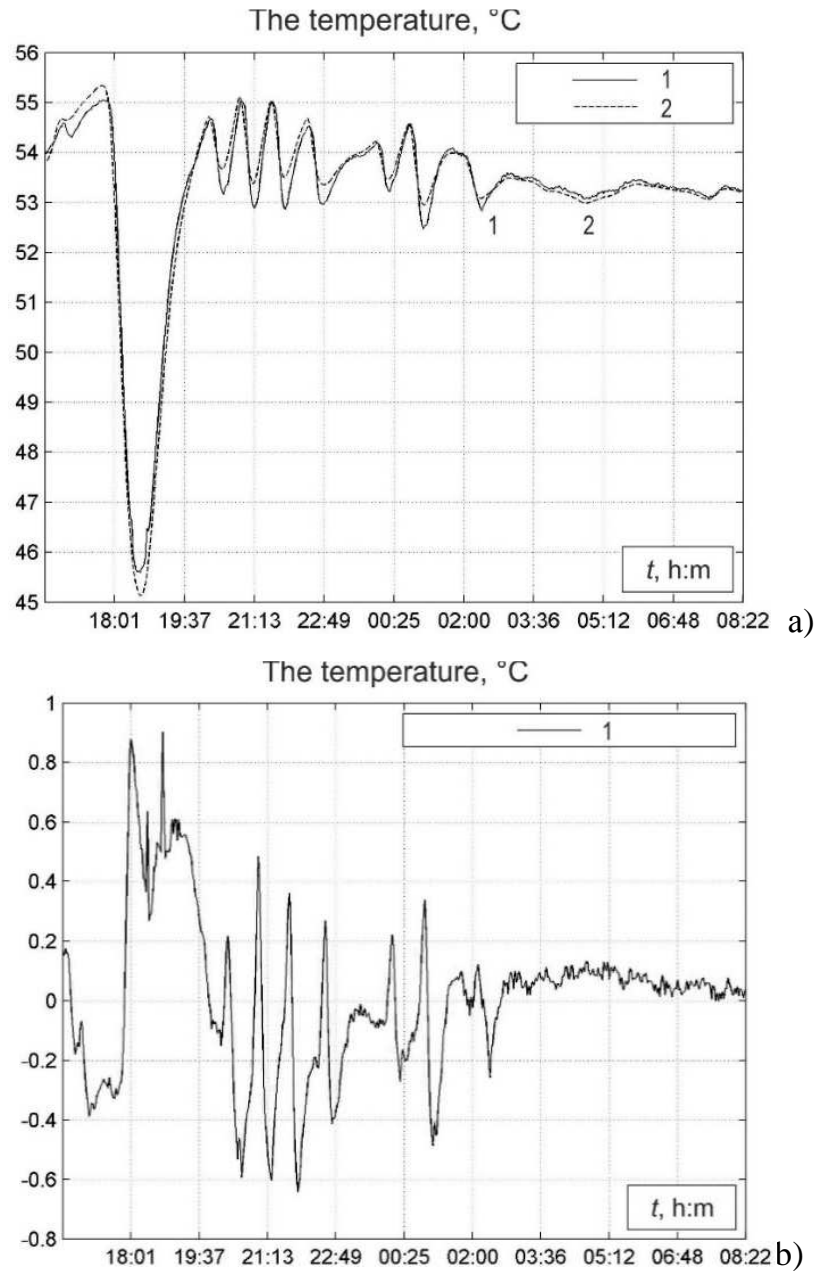

Fig. 7. Comparative graphs: $a$-coolant temperatures in the return pipe of the heating system ( 1 - experimental, 2 - mathematical), $b$ - residual. 
The analysis of Fig. 7 shows that the maximum deviation of experimental and calculated temperatures does not exceed 1 ${ }^{\circ} \mathrm{C}$, what in general corresponds to the accuracy of regulation in existing systems on the basis of electronic controllers with weather compensation.

\section{CONCLUSION}

The estimated coefficients of the model during functioning of the system may slightly vary, for example, due to the outer air temperature variations, change of enclosure types, reconstruction of the pipeline system, etc. Nevertheless, the given mathematical model is easy-to-use to obtain analytic solutions in modelling of building heating systems, although it has some errors (Fig. 7, b). Consequently, such representation of the controlled object is advisable to apply for the heating systems with a small pipe range, typical for distributed heating systems. The given approach is the basis for mathematical and simulation modelling of distributed power systems of buildings with the purpose of rational consumption of energy resources. The obtained results show that it is possible to construct distributed groups of buildings with various levels of automation.

\section{Acknowledgment}

The work is realized within the framework of the Program of flagship university development on the basis of Belgorod State Technological University named after V.G. Shoukhov with the use of equipment of the High Technology Centre at BSTU named after V.G. Shoukhov.

\section{References}

[1] D. Rodrik, Industrial Policy for the Twenty-First Century. Working Paper Series rwp04-047, Harvard University, J.F. Kennedy School of Government, 2004.
[2] J.A. Tabunschikiv, M.M. Brodach, N.V. Shilkin, Energy-efficient buildings, M.: ABOK-PRESS, 2003, p. 200.

[3] A.V. Belousov, S.N. Glagolev, J.A. Koshlich, A.B. Bystrov, "Energy saving demonstration zone of BSTU named after V.G. Shoukhov - a basis for development of energy-efficient flows in the region," Energy saving. Power engineering. Energy audit, 10 (116), pp. 10-17, 2013.

[4] Making applications future proof, all our knowledge - is now yours. Date Views 03.12 .2015 http://heating.danfoss.com/PCMPDF/VGHZA202 lores.pdf

[5] Electronic regulators, dispatching and electric control means. Product catalogue rc.08.e10.50, M.: LLC “Danfoss", 2016, p. 304.

[6] A.N. Potapenko, A.S. Soldatenkov, E.A. Potapenko, "Mathematical modelling of heating processes of a distributed goup of buildings with different schemes of heat consumption," Bulletin of Samara scientific centre of the Russian Academy of Science, vol.13, №4(4), pp. 998-1002, 2011.

[7] P. A. Strizhak, M. N. Morozov, "Energy efficience of building heating system with deiiferent methods of heat consumption regulation, "Scientific and technical bulletin of SPBGPU, 3(202), pp. 88-96, 2014.

[8] The thermal conditions modeling of the building blocks of the South Ural State University's educational complex. Materiály IX mezinárodní vědecko -praktická konference «Efektivní nástroje moderních věd 2013». -Díl 42. Technické vědy. -Praha. Publishing House «Education and Science» S.r.o, pp. 75-79.

[9] E.A. Potapenko, A.S. Soldatenkov, "Development of structure of automatic regulator in building heating systems for improvement of energy efficiency", Bulletin of BSTU named after V.G. Shoukhov, 2, 2011, pp. 155-160.

[10] N.V. Dolgov, A.A. Oleksjuk, Z.V. Udovichenko, D. V. Vybornov, 'Experimental studies of flow distribution at the automated control stations with three-circuit heat exchanger," Sciences of Europe, 5(5), pp. 77-84, 2016.

[11] A. Oppenheim, Discrete Time Signal Processing Third Edition, Upper Saddle River, NJ: Pearson Higher Education, Inc., 2010, p. 504.

[12] E.A. Robinson, S. Treitel, "Digital Imaging and Deconvolution: The $\mathrm{ABCs}$ of Seismic Exploration and Processing Digital Imaging and Deconvolution: The ABCs of Seismic Exploration and Processing," SEG Books, 163, pp. 375-376, 2008. 